\title{
Liver cirrhosis: A seven year follow-up
}

\author{
TS PAUl Tran, MD, S Victor FEINMAN, MS, MD, FRCPC, BARNET BERris, MS, MD, FRCPC
}

TSP TRAN, SV FEINMAN, B BERRIS. Liver cirrhosis: A seven year follow-up. Can J Gastroenterol 1991;5(1):11-14. The status of 121 patients who were found to have liver cirrhosis on liver biopsy in 1981 was assessed seven years later. The etiology of the cirrhosis was alcoholic in $52 \%$, cryptogenic in $29.8 \%$, hepatitis B-related in $9.1 \%$ and miscellaneous in $9.1 \%$. In 1981, jaundice was present in 55 patients $(45.8 \%)$, ascites in $52(43 \%)$, gastrointestinal bleeding in $25(20.7 \%)$ and encephalopathy in $10(8.3 \%)$. During the following seven years an additional 20 patients developed ascites, 15 gastrointestinal bleeding, 32 encephalopathy and three hepatocellular carcinoma. The mortality rate was $43.8 \%$ at five years and $53.7 \%$ at seven years. The principal cause of death was liver failure $(40 \%)$, followed by nonliver causes $(32.3 \%)$ and gastrointestinal bleeding $(13.9 \%)$. One patient died of hepatocellular carcinoma. Patients who survived seven years had fewer complications when seen in 1981 than those who died during this period $(\mathrm{P}<0.025)$. It is concluded that, in Toronto, cirrhosis is often caused by ethanol abuse and hepatitis B infection; that it is associated with significant morbidity and mortality; and that the number of complications when the patient is first seen may be a useful indicator of prognosis. Since many cases of cirrhosis are preventable, the authors suggest that efforts directed towards prevention of cirrhosis may be more rewarding than those directed towards therapy.

Key Words: Cirrhosis, Complications, Mortality rate, Prognosis

\section{Cirrhose du foie: Suivi à 7 ans}

RESUME: L'état de 121 patients chez qui une cirrhose du foie avait été diagnostiquée d'après une biopsie hépatique en 1981 a été évalué sept ans plus tard. La cirrhose était attribuée à l'alcoolisme chez $52 \%$, cryptogénique chez 29,8 $\%$, reliée à l'hépatite virale de type $\mathrm{B}$ chez $9,1 \%$ et d'origines diverses chez 9,1 $\%$ des sujets. En 1981, on relevait un ictère chez 55 patients $(45,8 \%)$, une ascite chez 52 (43\%), une hémorragie digestive chez $25(20,7 \%)$ et une encéphalopathie chez 10 patients $(8,3 \%)$. Au cours des sept années suivantes, 20 autres patients ont développé une ascite, 15 des hémorragies digestives, 32 une encéphalopathie et 3 un carcinome hépatocellulaire. Le taux de mortalité était de $43,8 \%$ à 5 ans et de $53,7 \%$ à sept ans. La cause principale des décès était linsuffisance hépatique (40\%), suivie par les causes non hépatiques $(32,3 \%)$ et

Liver Study Unit, Department of Medicine and Research, Mount Sinai Hospital, University of Toronto, Toronto, Ontario

Correspondence and reprints: Dr SV Feinman, Liver Study Unit, Mount Sinai Hospital, 600 University Avenue, Suite 652, Toronto, Ontario M5G $1 \times 5$

Received for publication May 14, 1990. Accepted January 14, 1991
【 IVER CIRRHOSIS IS A SIGNIFICANT cause of mortality and morbidity. Despite progress in the medical and surgical therapy of ascites, portal hypertension and variceal bleeding, five year survival rates are still in the range of $50 \%$ when combined etiologies are considered (1-7). The present study was an attempt to characterize and assess morbidity and mortality in a group of patients in whom liver cirrhosis had been diagnosed seven years previously.

The authors were able to trace 121 of 176 patients in whom a diagnosis of cirrhosis was made on liver biopsy in 1981. In this group the authors studied: the distribution of the varieties of cirrhosis; the prevalence of complications at the time of initial biopsy and over the ensuing seven years; the mortality rate at five and seven years after biopsy; the causes of death; and the relationship of the number of complications to prognosis.

\section{PATIENTS AND METHODS}

Between February 1, 1981 and January 31, 1982, 718 patients being investigated for the presence of liver disease had diagnostic liver biopsies in six Toronto teaching hospitals. In 176 patients, biopsies were diagnostic of cirrhosis. Patients with a diagnosis of hepatocellular carcinoma were excluded. These patients were drawn from a larger study of markers and risk factors for hepatitis B (8). Information collected included age, gender, etiology of cirrhosis, complications, presence of 
les hémorragies digestives $(13,9 \%)$. Un patient est décédé d'un carcinome hépatocellulaire. Les patients qui ont survécu sept ans avaient moins de complications quand ils ont consulté en 1981 que ceux qui sont décédés durant cette période $(\mathrm{P}<0,025)$. On conclut qu'à Toronto la cirrhose est souvent causée par l'éthylisme et l'hépatite virale de type B; qu'elle est associée à une morbidité et à une mortalité significative; et que le nombre de complications relevées lors de la première consultation pourrait laisser présager le pronostic. Parce que de nombreux cas de cirrhose peuvent être évités, les auteurs suggèrent que les efforts investis dans la prévention pourraient s'avérer plus fructueux que ceux qui s'attachent au traitement.

\section{TABLE 1}

\begin{tabular}{|c|c|c|c|}
\hline & Traced $(n=121)$ & Lost $(n=55)$ & $P\left(\chi^{2}\right.$ or $\left.Z\right)$ \\
\hline Age (years) & 56.1 & 55.6 & \\
\hline Male/female & $1.14 / 1$ & $1.29 / 1$ & \\
\hline Etiology of cirrhosis & & & $>0.10$ \\
\hline Alcoholic & $52 \%$ & $54.5 \%$ & \\
\hline Cryptogenic & $29.8 \%$ & $21.8 \%$ & \\
\hline Post hepatitis B & $9.1 \%$ & $14.5 \%$ & \\
\hline Miscellaneous & $9.1 \%$ & $9.1 \%$ & \\
\hline \multicolumn{4}{|l|}{ Complications } \\
\hline Ascites & $43 \%$ & $44 \%$ & 0.45 \\
\hline Jaundice & $45.5 \%$ & $49 \%$ & 0.33 \\
\hline Gastrointestinal bleed & $20.7 \%$ & $27 \%$ & 0.18 \\
\hline Encephalopathy & $8.3 \%$ & $14.5 \%$ & 0.13 \\
\hline No complications & $28.9 \%$ & $25.5 \%$ & 0.32 \\
\hline \multicolumn{4}{|l|}{ Hepatitis B serology } \\
\hline Surface antigen positive & $4 \%$ & $9 \%$ & 0.12 \\
\hline All hepatitis B virus markers & $23.1 \%$ & $22 \%$ & 0.44 \\
\hline History of transfusion & $28.9 \%$ & $33 \%$ & 0.30 \\
\hline
\end{tabular}

markers of hepatitis B and history of transfusion.

From November 1988 to January 1989 the authors attempted to locate the 176 patients for re-study. The patient's physician was first contacted. If the physician had lost track of the patient, an attempt was made to contact the patient or the patient's family. The authors were able to locate 121 of the 176 patients and obtained information regarding the presence of additional complications such as ascites, gastrointestinal bleeding, hepatic encephalopathy and hepatocellular carcinoma between 1981 and 1988, as well as the date and cause of any deaths.

In order to determine whether the traced group was a valid sample representative of the entire group, a statistical comparison of the characteristics of the traced and lost groups was carried out. Age and gender distribution were similar. Etiology of cirrhosis in the traced and lost groups, as well as the number of complications between survivors and deceased patients, were compared statistically using the $\chi^{2}$ test. Initial complications, hepatitis B markers and history of transfusion in the traced and lost groups of patients were compared using the $\mathrm{Z}$ test.

\section{RESULTS}

One hundred and twenty-one patients were traced, and 55 were lost seven years after the diagnosis of cirrhosis was made on liver biopsy. Eightyeight patients were traced through their physicians; 18 were contacted directly; and 15 were traced through their families. When the characteristics of the traced and lost groups identified in 1981 were compared, there was no statistically significant difference between them (Table 1). This suggests that the traced group was representative of the entire group.

The etiology of cirrhosis in the traced patients was alcoholic in 63 $(52 \%)$, cryptogenic in $36(29.8 \%)$, post hepatitis B in $11(9.1 \%)$ and miscel. laneous in $11(9.1 \%)$. The distribution of etiologies in the miscellaneous group was one congestive, three post jejunoileal bypass, one lupoid, five primary biliary cirrhosis and one alpha- 1 antitrypsin deficiency. In 1981 the com. plications were jaundice in 55 patients, ascites in 52 , and encephalopathy in 10 . There was a history of gastrointestinal bleeding in 25 patients. Thirty-five patients had no complications, and none had evidence of hepatocellular carcinoma. Forty patients had no com. plications, 41 had one, 30 had two, seven had three, and two had four. Over the next seven years an additional 20 patients developed ascites, 15 gastrointestinal bleeding, and 32 encephalopathy. Three hepatocellular carcinomas were diagnosed (Table 2).

After seven years 65 patients had died $(53.8 \%)$. The five year mortality was $43.8 \%$. If one assumed that all 55 patients who were lost to follow-up died, the seven year mortality rate would be $68.2 \%$. The seven year mortality was $60.3 \%$ in alcoholic cirrhosis and $50 \%$ in cryptogenic cirrhosis. Three of the 11 patients with hepatitis $\mathrm{B}$ cirrhosis and six of the 11 patients in the miscellaneous group died. The major causes of death were liver failure $(40 \%)$, nonliver causes (cardiovascular, cerebrovascular and nonhepatic malig. nancies) $(32.3 \%)$, and gastrointestinal bleeding $(13.9 \%)$. One patient died of hepatocellular carcinoma. In $12.3 \%$ of patients, the cause of death was unknown.

Statistical comparison of the num. ber of complications per patient in 1981 between patients who survived and those who died showed that patients who survived had fewer complications than those who died $(\mathrm{P}<0.025)$ (Figure 1).

\section{DISCUSSION}

Alcoholic cirrhosis was present in $52 \%$ of the present study group and was the most common type of cirrhosis. Al. coholic cirrhosis is also the most com. 


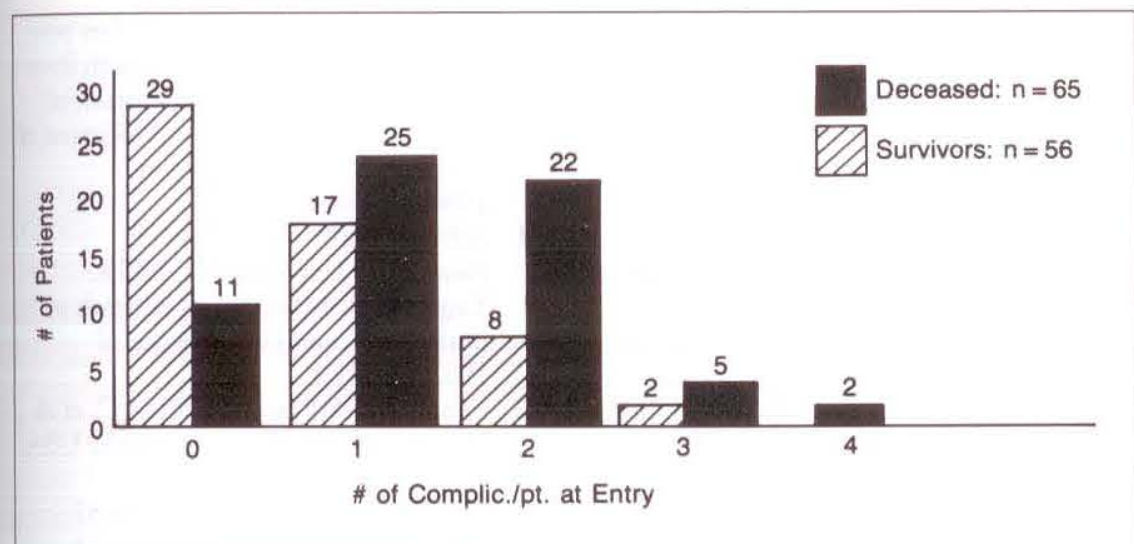

Figure 1) Comparison of number of initial complications (ascites, jaundice, gastrointestinal bleeding and encephalopathy) in the survivors and the deceased $(n=121) \cdot \chi^{2}$ value for distribution of number of complications for both groups: $\chi^{2}=12.94 ; d f=4 ; P<0.025$

\section{TABLE 2}

Complications in 1981 and new complications developing between 1981 and 1988

\begin{tabular}{llc}
\hline Complications & 1981 & 1988 \\
\hline Ascites & $52(43 \%)$ & 20 \\
Gastrointestinal bleeding & $25(20.3 \%)$ & 15 \\
Encephalopathy & $10(8.3 \%)$ & 32 \\
Hepatocellular carcinoma & 0 & 3 \\
\hline
\end{tabular}

mon type of cirrhosis seen in Europe. In studies from Britain and Scandinavia (3.5), alcoholic cirrhosis accounted for 50 to $54 \%$ of cirrhotics. In Japan, however, alcoholic cirrhosis appears to be a less frequent cause of cirrhosis than in Canada and Europe, and accounted for $33 \%$ and $39 \%$ of cirrhotics in two series (6,7). Cryptogenic cirrhosis accounted for $29.8 \%$ and hepatitis B-related cirrhosis accounted for $9.1 \%$ of the cirrhotics in the present series. In Japan, cryptogenic cirrhosis was present in $41 \%$ and $39.5 \%$ in two series, and hepatitis B-related cirrhosis was present in $21 \%$ and $24 \%(6,7)$. These findings may be accounted for by the higher prevalence of viral hepatitis B in Japan. The development of more sensitive serological markers for hepatitis B, such as the polymerase chain reaction and the new serological test for hepatitis C, will likely reshape the data in the cryptogenic group of cirrhotics. It is possible that the cirrhosis in a significant number of patients in this group may be due to previously unrecognized hepatitis B or C.

When the present patients were first studied in 1981, $71.1 \%$ had complica- tions of cirrhosis. Jaundice and ascites were most common, followed by gastrointestinal bleeding and encephalopathy. The frequency of complications was very similar in two studies reported from Britain $(1,5)$. Over the next seven years there were numerous additional complications, noted in Table 2.

Established cirrhosis has a high mortality rate. In the present patients it was $43.8 \%$ at five years and $53.7 \%$ at seven years. If it is assumed that all of the patients lost to follow-up had died, the seven year mortality rate would be increased to $68.2 \%$. In other studies the five year mortality ranges between 30 and $50 \%(9-11)$. The mortality rate is very similar in alcoholic $(60.3 \%)$ and cryptogenic cirrhosis (50\%). The numbers in hepatitis B and in the miscellaneous group of cirrhotics were too small to draw valid conclusions. In other studies the mortality rate appeared to be unrelated to etiology and was very similar in alcoholic, cryptogenic and hepatitis B-related cirrhosis (7-9).

The major causes of death attributable to liver disease in the present patients were liver failure in $40 \%$, gastrointestinal bleeding in $13.9 \%$ and hepatocellular carcinoma in one patient. In $12.3 \%$ the cause was unknown, and $32.3 \%$ died from nonhepatic causes. Similar findings have been reported from Scandinavia (10), but in Japan there was a much higher mortality due to hepatocellular carcinoma (7). In the present study only one patient died of hepatocellular carcinoma over seven years. The mortality rate from hepatocellular carcinoma following cirrhosis varies greatly. It was only $4 \%$ in the United States (11) and as high as $44 \%$ in Japan; however, this was over a 26 year follow-up (7). Hepatocellular carcinoma is much more prevalent in countries such as Japan, where there is a high prevalence of hepatitis B. It is clear that the incidence of hepatocellular carcinoma is increasing, both in the Far East (7) and in the West (12-14), possibly because of prolonged survival in cirrhotic patients, as well as improved means of detection and awareness of causal relationships.

There have been a number of studies which have attempted to identify prognostic indicators in cirrhosis. This is now of some importance, since it may help to identify patients who will benefit from a variety of treatment modalities, particularly liver transplantation. Clinical, biochemical and morphological factors have been assessed often in combination (15), and until recently Child's criteria have been used most frequently (16). The present authors have shown that when the frequency of initial complications in patients who survived was compared to the frequency in those who had died seven years later, there were significantly fewer complications in the survivors. Thus, assessment of the number of complications when patients are first seen may be a useful bedside indicator of prognosis, the predictive value of which should be validated prospectively in an independent series of patients.

In conclusion, the authors have shown that in Toronto, cirrhosis is often ethanol related, cryptogenic or due to chronic hepatitis B infection; that complications are frequent; and that mortality is still high. They have 
also shown that the number of complications when the patient is first seen may be a useful clinical indicator of prognosis and may help to identify candidates for liver transplantation. Since a significant number of cases of cirrhosis are preventable, the authors suggest that efforts directed towards prevention of cirrhosis may be more rewarding than those directed towards therapy.

ACKNOWLEDGEMENTS: We thank Drs A Newman, L Blendis, K Jeejeebhoy, B Taylor, RE Warren, JE Heathcote and MM Fisher for their cooperation in allowing us to study charts of their patients, S Borjarksi for the initial data collection, Dr S Bull for valuable statistical advice, F Strain for secretarial assistance and Thelma Berris for editorial assistance.

\section{REFERENCES}

1. Stone WD, Islam NRK, Paton A. The natural history of cirrhosis. Experience with an unselected group of patients. QJ Med 1960;37:119-32.

2. Brick IB, Palmer ED. One thousand cases of portal cirrhosis of the liver. Implications of esophageal varices and their management. Arch Intern Med 1964;113:501-11.

3. Saunders JB, Walters JRF, Davis AP, Paton A. A 20-year prospective study of cirrhosis. Br Med J 1981;282:263-6.

4. Olsson R. The natural history of esophageal varices. A retrospective study of 224 cases with liver cirrhosis. Digestion 1972;6:65-74.

5. Sanchez GC, Baunsgarrd P, Lundborg DJ. A comparison between clinical diagnosis and histopathological findings in liver biopsies. Scand J Gastroenterol 1980;15:985-91.

6. Ohnishi K, Iida S, Iwama S, et al. The effect of chronic habitual alcohol intake on the development of liver cirrhosis and hepatocellular carcinoma Relation to hepatitis B surface antigen carriage. Cancer 1982;49:672-7.

7. Tanaka $R$, Itoshima $T$, Nagashima $H$. Follow-up study of 582 liver cirrhosis patients for 26 years in Japan. Liver 1987;7:316-24.

8. Coates RA, Halliday ML, Rankin JG, Feinman SV. Hepatitis B markers and risk factors for hepatitis B in liver biopsy patients. Clin Invest Med 1986;9:65-70.

9. Tsuji Y, Koga S, Ibaayashi H. A follow-up study on the prognosis of liver cirrhosis. Nippon Shokakibyo Gakkai Zasshi 1985;82:434-40.

10. Okazaki I, Maruyama K, Funatsu K,
Kashiwazaki K, Tsuchiya M. Ten year survival rate of 131 patients with liver cirrhosis excluded the association of liver carcinoma at the establishment of diagnosis. Gastroenterol Jpn 1980;15:350-4.

11. Schlichting P, Christensen E, Fauerholdt L, Poulsen H, Juhl E, Tygstrup N. Main causes of death in cirrhosis. Scand J Gastroenterol 1983;18:881-8.

12. Omata M, Ashcavai M, Liew C, et al. Hepatocellular carcinoma in the USA, etiological considerations. Gastroenterology 1979;76:279-87.

13. Bartoloni St, Omer F, Giannini A, Napoli P. Hepatocellular carcinoma and cirrhosis: A review of their relative incidence in a 25-year period in the Florence area. Hepatogastroenterology 1984;31:215-7.

14. Peters RL. Pathology of hepatocellulat carcinoma. In: Okuda K, Peters RL, eds. Hepatocellular Carcinoma. New York: Wiley, 1976:107-68.

15. LeCompte Y, Metreau JM, Sancho HS, Bismuth H. Prediction of mortality in cirrhosis of the liver. Surg Gynecol Obstet 1974;139:529-30.

16. Christensen E, Schlichting P, Fauerholdt L, et al. Prognostic value of Child-Turcotte criteria in medically treated cirrhosis. Hepatology 1984:4:430-5 


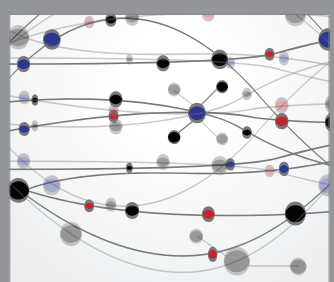

The Scientific World Journal
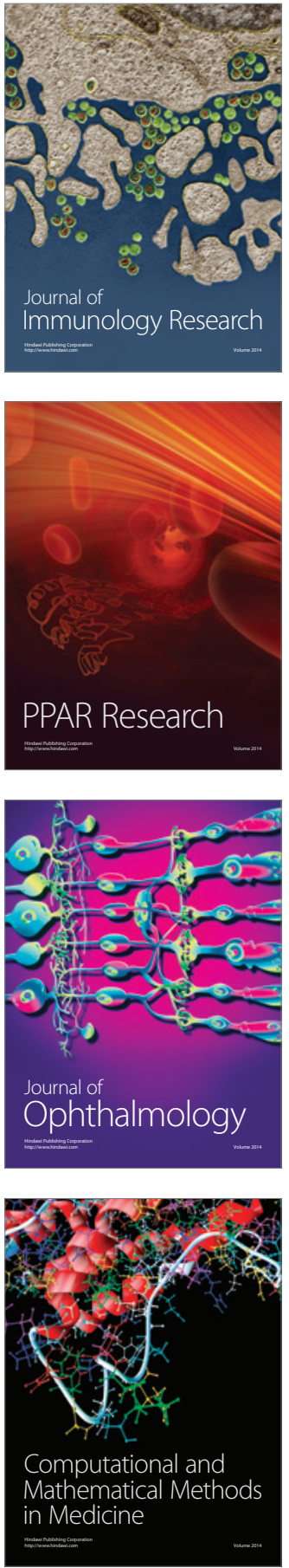

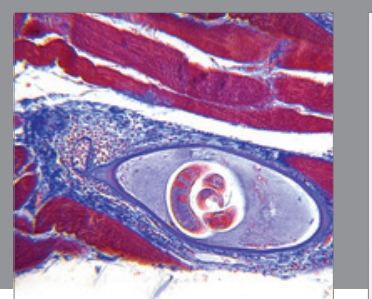

Gastroenterology Research and Practice

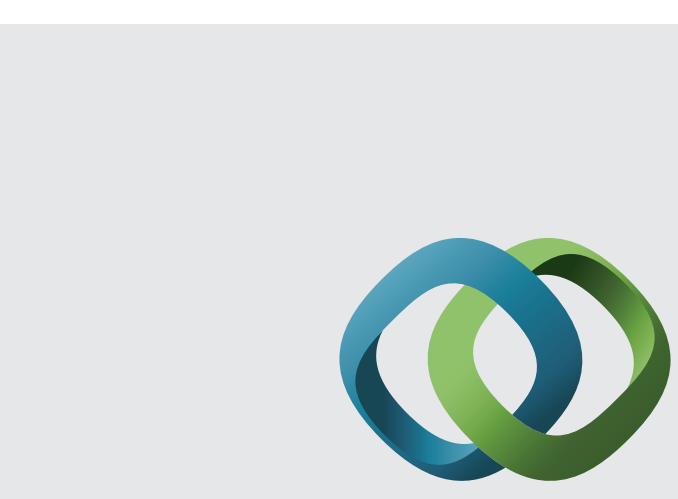

\section{Hindawi}

Submit your manuscripts at

http://www.hindawi.com
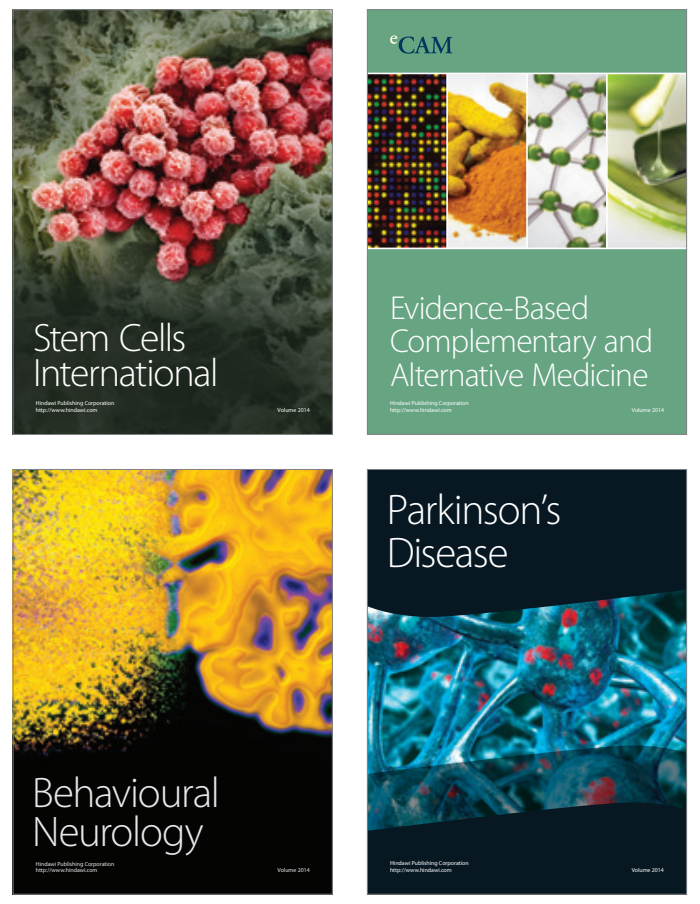
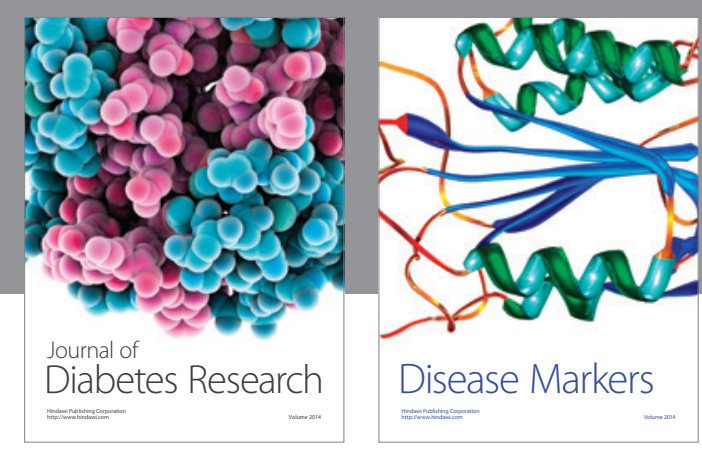

Disease Markers
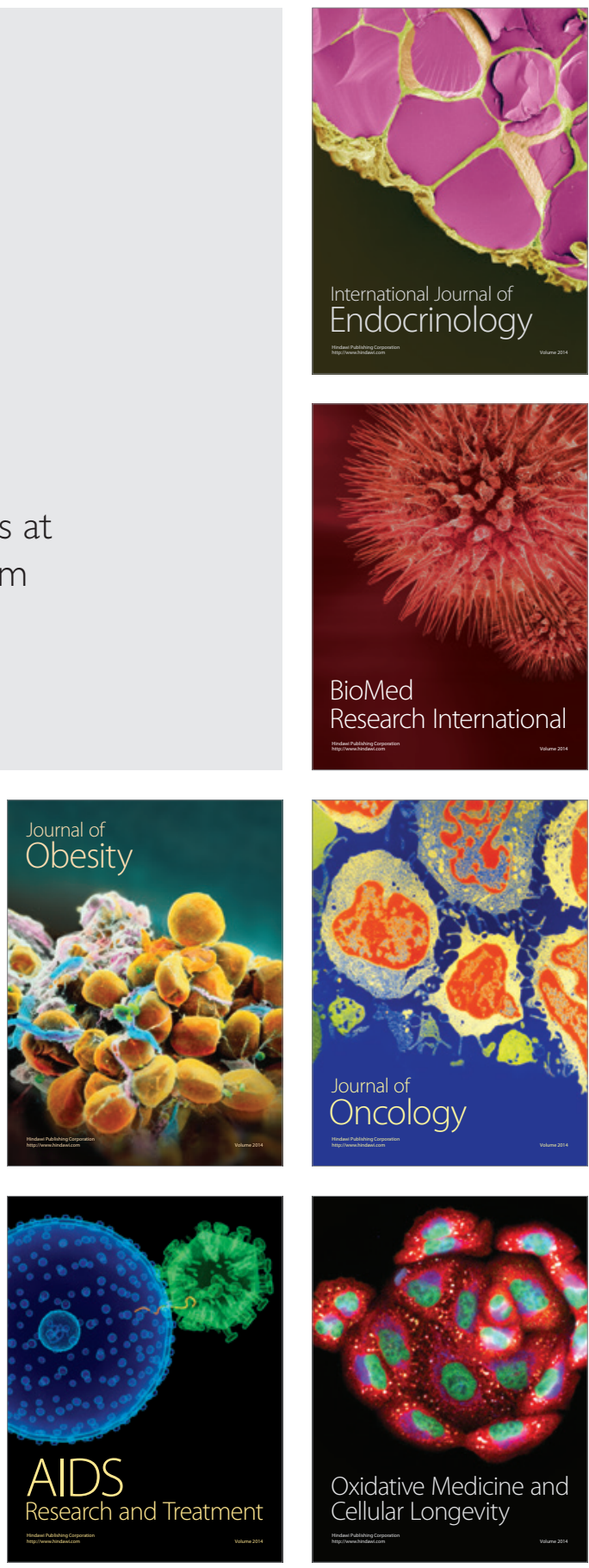